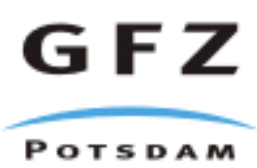

Originally published as:

Hagg, W., Mayer, C., Lambrecht, A., Helm, A. (2008): Sub-debris melt rates on southern Inylchek Glacier, central Tian Shan. - Geografiska Annaler, Series A: Physical Geography, $90,1,55-63$

DOI: 10.1111/j.1468-0459.2008.00333.x. 


\title{
SUB-DEBRIS MELT RATES ON SOUTHERN INYLCHEK GLACIER, CENTRAL TIAN SHAN
}

\author{
BY \\ WILFRIED HAGG ${ }^{1}$, CHRISTOPH MAYER ${ }^{2}$, ASTRID LAMBRECHT ${ }^{3}$, ACHIM HELM $^{4}$ \\ ${ }^{1}$ Department of Geography, University of Munich, Germany \\ ${ }^{2}$ Commission for Glaciology, Bavarian Academy of Sciences and Humanities, Munich, \\ Germany \\ ${ }^{3}$ Institute for Meteorology and Geophysics, University of Innsbruck, Austria \\ ${ }^{4}$ GeoForschungsZentrum Potsdam, Germany
}

Hagg, W., Mayer, C., Lambrecht, A. and Helm, A., :Geografiska Annaler,

\begin{abstract}
Melt rates of glacier surfaces are strongly influenced by the existence of a debris cover. Dependent on thickness and other physical parameters the debris layer can enhance or reduce ablation as compared to bare ice conditions. Supraglacial moraines appear very frequently on Central Asian glaciers, highly affecting water yield from these high mountain regions. In summer 2005, a network of 22 ablation stakes was drilled into locations with varying debris thicknesses on Southern Inylchek glacier in the central Tian Shan. Mean ablation rates varied from 2.8 to $6.7 \mathrm{~cm} / \mathrm{d}$, strongly correlated with moraine thickness. Parallel observation of air temperature allowed the application of a simple degree-day approach and the calculation of ablation rates. Efforts to improve calculations of melt rates by incorporating relative air humidity to account for latent heat fluxes failed. This proves that air temperature is already a very good melt indicator. Ice albedo measurements show that reflectivity might be controlled by the occurrence of evaporation or condensation, but this topic needs further investigation.
\end{abstract}

\section{Introduction}

Glaciers are important water resources in high mountain regions. In Central Asia, their role is of special relevance because the Tian Shan and Pamir mountain systems are surrounded by arid lowlands that highly depend on glacier melt water during the growing season as irrigation and drinking water. Inylchek glacier is located in the catchment of Aksu river, a main tributary of Tarim river. According to the Chinese Glacier Inventory, glaciers in the Tarim basin cover an area of almost $20.000 \mathrm{~km}^{2}$ and provide $13.3 \mathrm{~km}^{3}$ meltwater per year, contributing 39\% to total river runoff (Yang 1991). This water is essential for irrigation in vast agricultural areas. Aksu basin has shown a moderate areal glacier retreat $(-3,3 \%)$ from 1963-1999, with a dominant shrinkage of small glaciers (Liu et al., 2006). 
For the estimation of future water yield from those headwaters it is of great importance to investigate the interaction between atmosphere and ice, especially with respect to melt water formation. Many Central Asian glaciers are characterised by a supraglacial moraine that affects surface energy balance and thus runoff generation. With the currently observed global warming and worldwide glacier retreat the number of debris covered glaciers and thus the effect of the debris covers on overall runoff formation will increase in the future.

Although the physical processes are well known, quantification of sub-debris ablation is a difficult task due to the large amount and great spatial variability of the factors involved. Therefore, the estimation of melt under moraine in areas with sparse data requires a simple parametrisation, e.g. with a temperature index approach as performed in earlier studies (Singh et al. 2000, Kayastha et al. 2000, Mihalcea et al. 2006). For this purpose it is important to collect field data from glacier regions with differing climate, altitude, lithology and debris patterns to develop simplified functions which describe and quantify the process. This paper presents results from Southern Inylchek glacier in the highly continental central Tian Shan, where sub-debris ablation was measured with stakes and simulated using air temperature and water vapour pressure.

\section{Ablation under a debris layer}

Ablation summarizes all processes which lead to a mass loss of glacier ice, the two most important of which are melt and evaporation. In very dry conditions, sublimation can occur. Other energy sources such as heat from rain or geothermal fluxes play a minor role and are not regarded here. The physical description of ablation uses the energy balance equation with its main terms radiation balance (the sum of shortwave and longwave radiation) and the fluxes of sensible heat and latent heat (evaporation and condensation). This equation allows the calculation of ablation, but requires many parameters (Kraus 1966). To record all energy fluxes involved at one location, a large array of instruments has to be installed, which means great logistic effort especially in remote mountain regions. Kayastha et al. (2000) applied the energy balance method at Khumbu glacier, Himalaya and experienced serious difficulties. Another problem is the spatial variability of the glacier surface and resulting melt rates which complicates the extrapolation of a point measurements to a larger area.

The existence of a debris cover introduces even more parameters such as thickness, temperature and thermal conductivity of the covering layer, which are controlled e.g. by albedo, density and moisture conditions. Kraus (1966, 1975) delivered a comprehensive theoretical descripton of the functions and parameters involved. Nakawo and Young (1981, 1982) developed a more practical model which allows to estimate ablation under a debris mantle only from surface temperature and external meteorological parameters, without knowing physical characteristics of the debris. Surface temperature itself is difficult to determine, Nicholson and Benn (2006) define this term numerically by iteration, using the energy balance equation.

Very thin layers of debris increase ablation rates due to their lower albedo compared to ice; once a critical thickness is reached a shielding effect begins to dominate, which insulates the underlying ice and strongly reduces melt rates (Østrem 1959). The hyperbolic dependence 
between debris thickness and melt was theoretically explained by Khodakov (1972) and experimentally confirmed by many researchers, but the critical thicknesses found in literature range from $2 \mathrm{~cm}$ on Dome glacier in the Canadian Rockies (Mattson 2000) to 7-8 cm on Djankuat glacier, Caucasus (Popovnin and Rozova 2002). This variability is due to differences in lithology and/or weather conditions. Within a certain range of debris thicknesses, meteorological conditions can determine if a moraine covered location has higher or lower ablation rates than a neigbouring spot of bare ice. The same boulder can build a glacier table during warm and dry periods or a melt hole at opposite weather conditions (Kraus 1966).

Evolving from colluvial material, from thrust moraines (emergence of sublacial moraine) and from melting out of englacial moraine, debris cover increases towards the glacier snout, altering the effect on ablation. As soon as the moraine cover reaches a thickness of about 1.5$2 \mathrm{~m}$, ice melt practically stops. Bozhinskiy et al. (1986) introduced a mathematical model capable to describe the dynamic evolution of a debris mantle from englacial moraine. Increased ablation leads to an acceleration of debris cover genesis by melting out of englacial moraine, which again lowers ablation. This negative feedback protects glacier ice under unfavourable climate conditions. At Djankuat glacier in Caucasus, an increase of summer air temperature by $1^{\circ} \mathrm{C}$ from 1968-1999 could not enhance ablation, because the area of debris cover more than doubled during the same period (Popovnin and Rozova 2002). Another hydrological effect of a debris cover is the reduction of the year-to-year variation in runoff, which is due to the lower thermal conductivity in dry years and vice versa (Mattson 2000).

\section{Geographical setting}

Southern Inylchek glacier, located at approximately $42^{\circ} 10^{\prime} \mathrm{N}$ and $79^{\circ} 50^{\prime} \mathrm{E}$, ranges in altitude from $2900 \mathrm{~m}$ a.s.l. to $7400 \mathrm{~m}$ a.s.l. and covers a surface area of almost $500 \mathrm{~km}^{2}$. This $60 \mathrm{~km}$ long valley type glacier is the largest ice mass of the Pobeda-Khan Tengri massif in Central Tian Shan. Around $14 \mathrm{~km}$ upstream from the snout, runoff from Northern Inylchek glacier is dammed in a side valley and forms the largest glacial lake of Central Asia. This lake is completely drained almost every year through a sublacial system, forming massive jökulhlaups. The great mass loss due to the relative warm lake water combined with calving processes leads to an acceleration of ice velocities on the right part of the Southern Inylchek ice stream, where ice flow turns around in a $90^{\circ}$ angle into the side valley to form the ice dam (Fig. 1). The left part of the glacier flows straight to the snout, but velocities are almost reduced to zero (see also Mayer et al., same issue). 


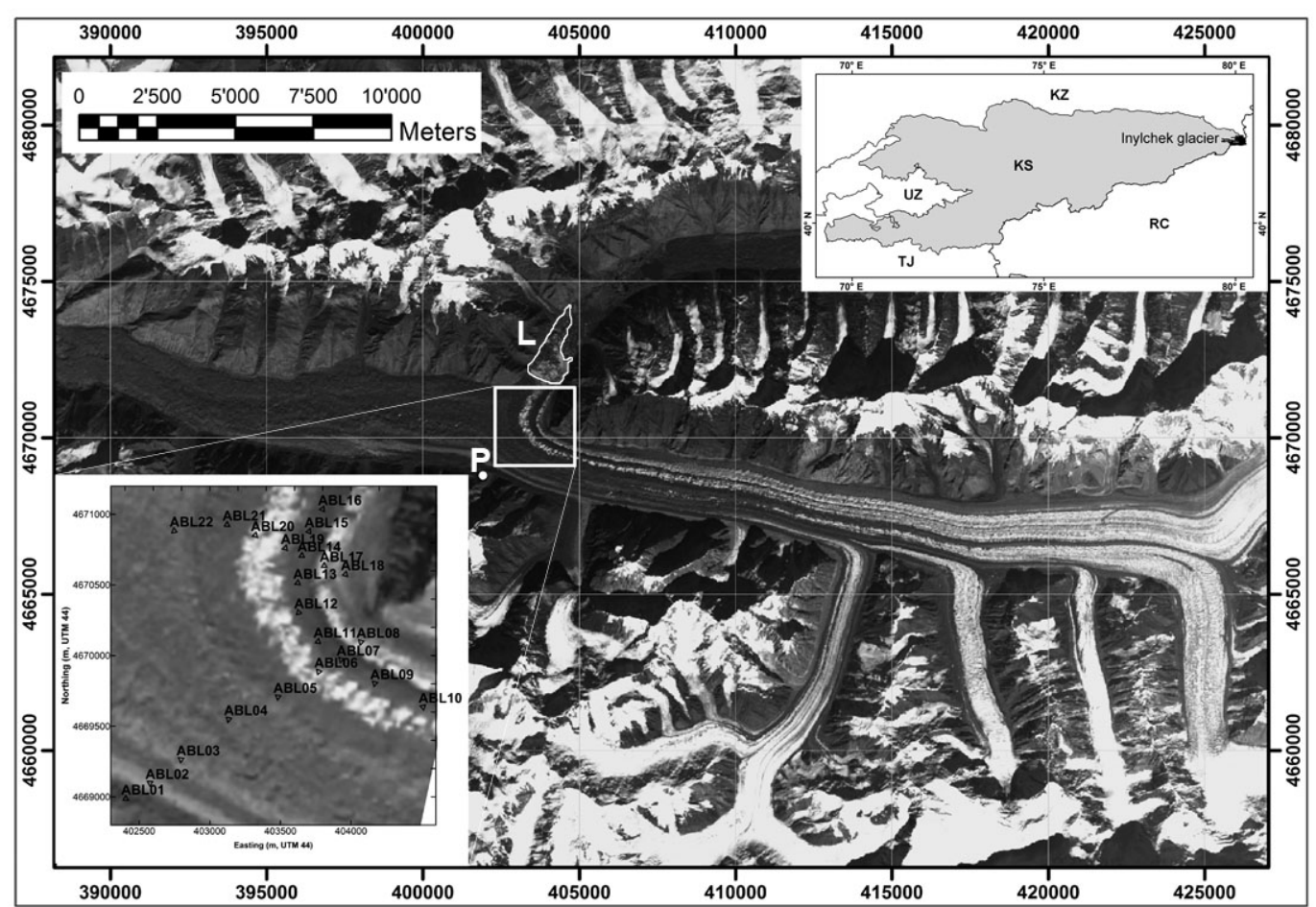

Fig. 1. Aster image of the investigation area with camp "Paliana" $(M)$, Lake Merzbacher $(L)$ and stake network.

As many glaciers in Central Asia, Southern Inylchek posesses an extensive moraine cover.

Starting as medial moraines in the upper reaches of the glacier, debris cover forms longitudinal ramparts that gradually transform into a uniform cover with decreasing altitude. On the left part an almost complete debris cover is already reached about $7 \mathrm{~km}$ upstream of the transfluence at Lake Merzbacher, the part which flows into the lake still has two distinct stripes of bare ice at the ice dam. This difference can be explained by the higher ice flux of the right stream, due to the mass loss into the lake.

\section{Ablation measurements}

Ablation was measured from 30 July to 10 August 2005 at 22 stakes that were placed into the ice using a steam drill. Locations with differing debris cover were chosen, from bare ice to 35 cm moraine thickness. To eliminate the influences of aspect and slope, which can be as important as total debris thickness (Mihalcea et al. 2006) the stakes were set at more or less horizontal surfaces. At some stakes readings were taken twice a day, whereas at more remote spots only the total amount during the observed period was recorded. Melt rates varied from 2.8 to $6.7 \mathrm{~cm} / \mathrm{d}$ with a mean of $4.4 \mathrm{~cm} / \mathrm{d}$. At the stake with $35 \mathrm{~cm}$ debris cover readings were biased by repeated erosion of debris after rainfall. During the time between these events melt rates between 0 and $2 \mathrm{~cm} / \mathrm{d}$ were measured. A mean value of $0.9 \mathrm{~cm} / \mathrm{d}$ was assumed for this stake, which corresponds exactly with relative ice melt intensities under moraine covers presented by Konovalov (2000) for Central Asia. Fig. 2 shows the relation between debris cover and melt rates. 


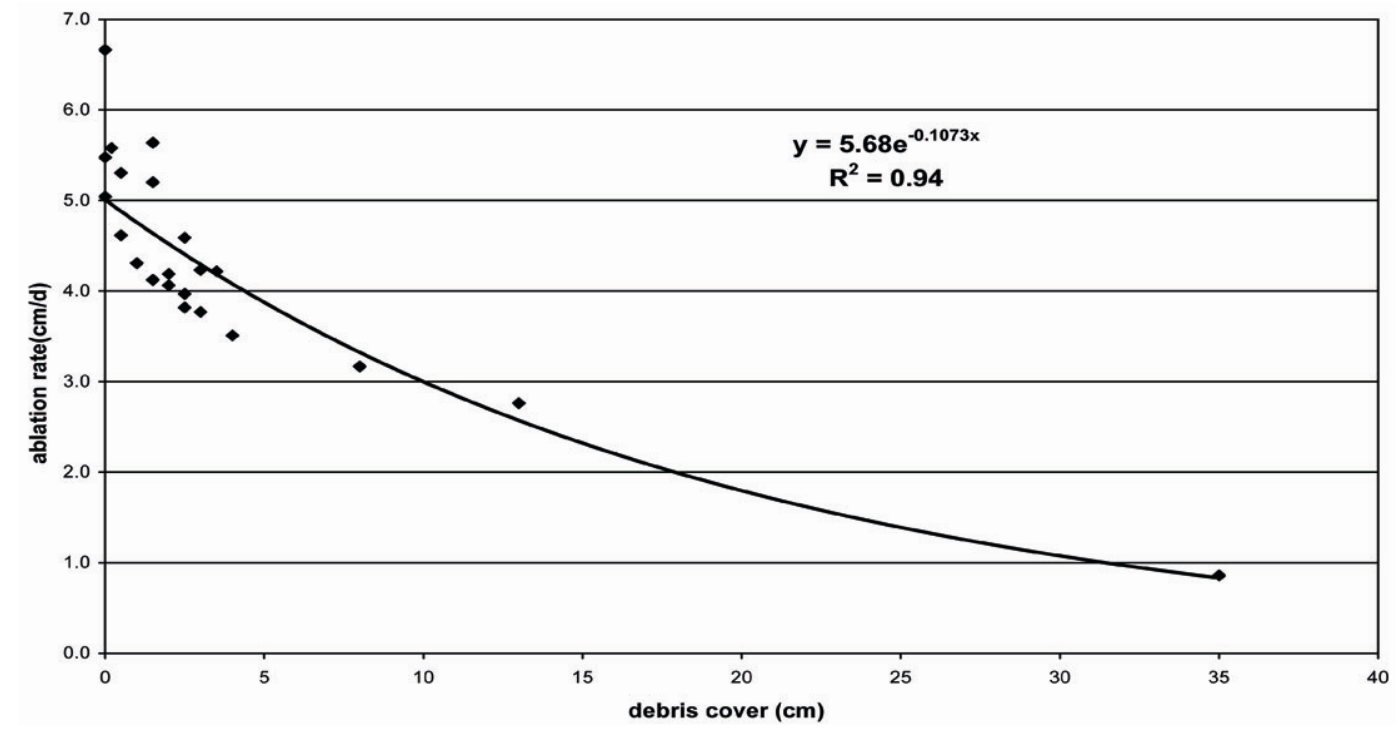

Fig. 2. Correlation of ablation rate and debris cover.

Enhancement of melt under a thin debris layer could not be verified by the measurements. The average ablation rate for the three locations of bare ice $(5.7 \mathrm{~cm} / \mathrm{d})$ was not exceeded at any location where a debris cover of any thickness existed. This is in agreement with the results of Mihalcea et al. (2006) and probably due to the fact that bare ice locations were not completely clean, but rather the presence of dust and cryoconite lowered albedo and thus increased absorption of solar energy.

The full record of measurements is visualised as cumulative ablation in Fig. 3. The saw-like profiles at some stakes arise from measurements on mornings and evenings and displays differences between day and night.

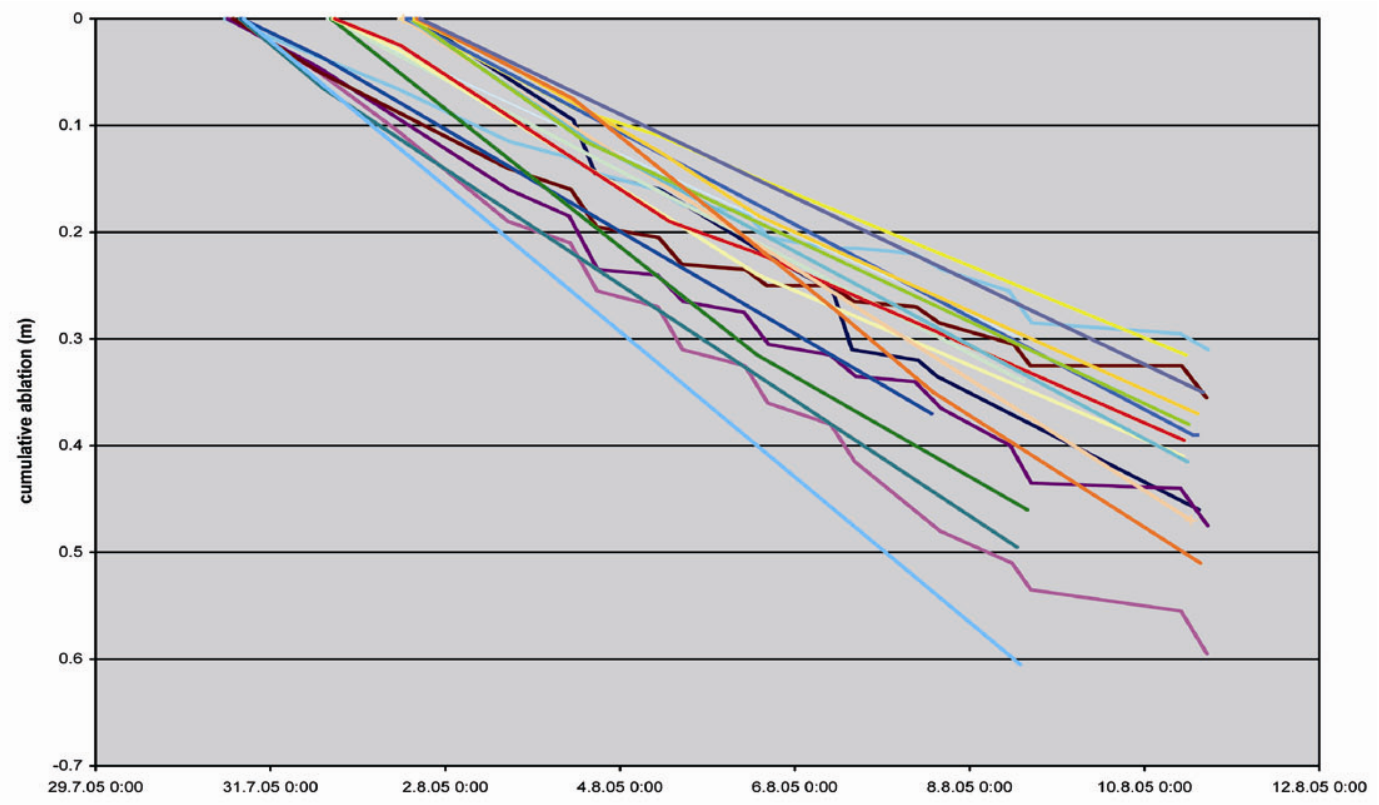

Fig. 3. Full record of ablation mesurements at 22 stakes, starting on three following days. 


\section{Meteorological measurements}

At base camp "Paliana", located on the lateral moraine at an altitude of $3400 \mathrm{~m}$ a.s.l. an automatic weather station (Vaisala PTU 200) was installed and operated from 31 July to 11 August. The station recorded air temperature, relative humidity and air pressure with a temporal resolution of one minute. A second weather station of the same type was located on the eastern shore of Lake Merzbacher, but this record was interrupted several times. Comparison of data in periods with both stations running showed good fit of the data, so some lake data were used to fill shorter data gaps in the Paliana camp. The full record of air temperature and humidity is shown in Fig. 4.

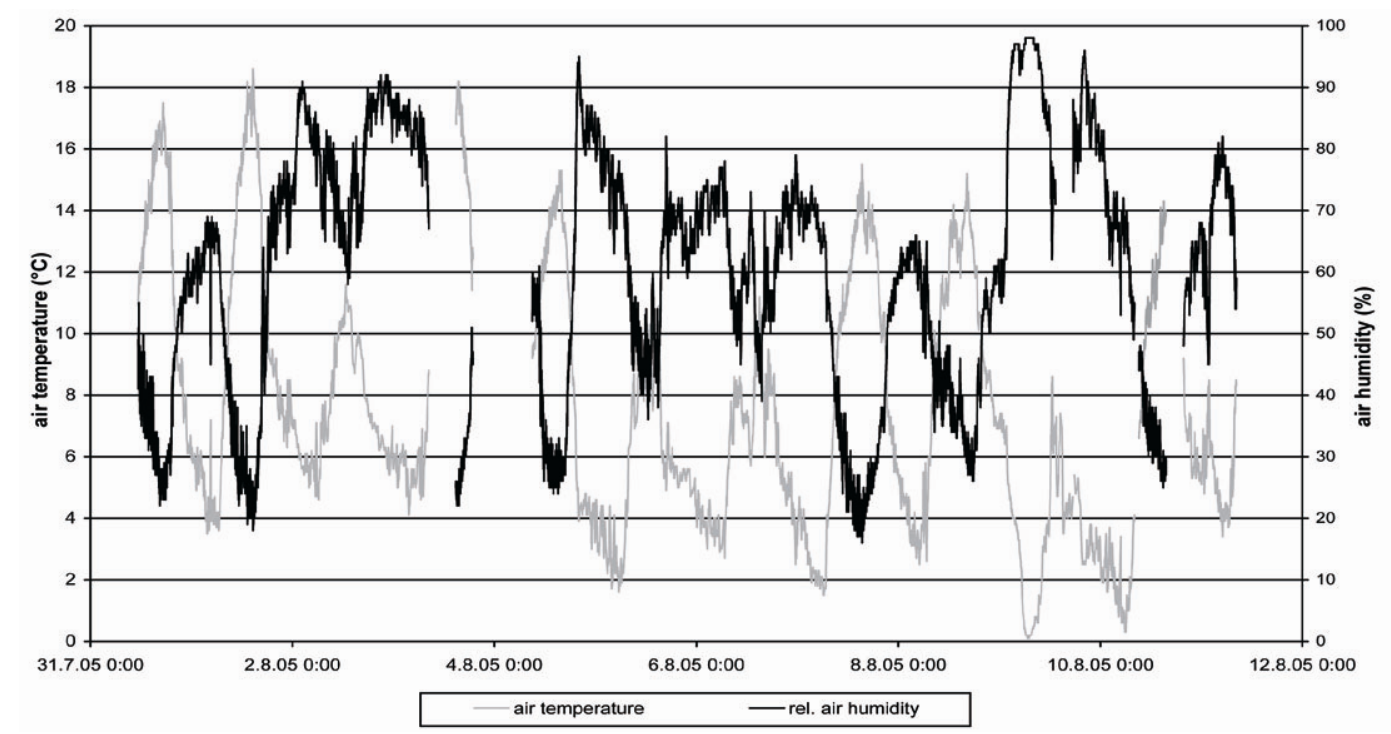

Fig. 4. Air temperature and relative air humidity at base camp "Paliana".

Daily means of air temperature ranged from $3.7^{\circ} \mathrm{C}$ to $9.7^{\circ} \mathrm{C}$, with an average of $7.6^{\circ} \mathrm{C}$. Absolute minimum and maximum temperatures were $0.1^{\circ} \mathrm{C}$ and $18.6^{\circ} \mathrm{C}$, respectively. Relative air humidity shows daily means from $40-86 \%$ and air pressure varies only slightly around $670 \mathrm{hPa}$.

\section{Degree-day approach}

A degree-day factor (DDF) can be used to calculate melt over larger areas only from air temperature, which can extrapolated fairly well to different altitudes due to rather constant lapse rates. DDF is calculated by dividing ablation by the sum of positive air temperatures (Braithwaite 1995). This so called temperature index method benefits from the fact that mean air temperature is a good melt indicator, because it is strongly connected to the most important energy sources in high alpine environments, i.e. solar radiation and sensible heat flux (Ohmura 2001).

The air temperature record allowed the calculation of degree-day factors for Southern Inylchek glacier, which ranged from 4.1 to $9.3 \mathrm{~mm} /\left(\mathrm{K}^{*} \mathrm{~d}\right)$ with a mean value of 6.1 $\mathrm{mm} /\left(\mathrm{K}^{*} \mathrm{~d}\right)$.

Fig. 5 compares measured ablation values with calculated ones, using the mean degree-day factor of 6.1. 


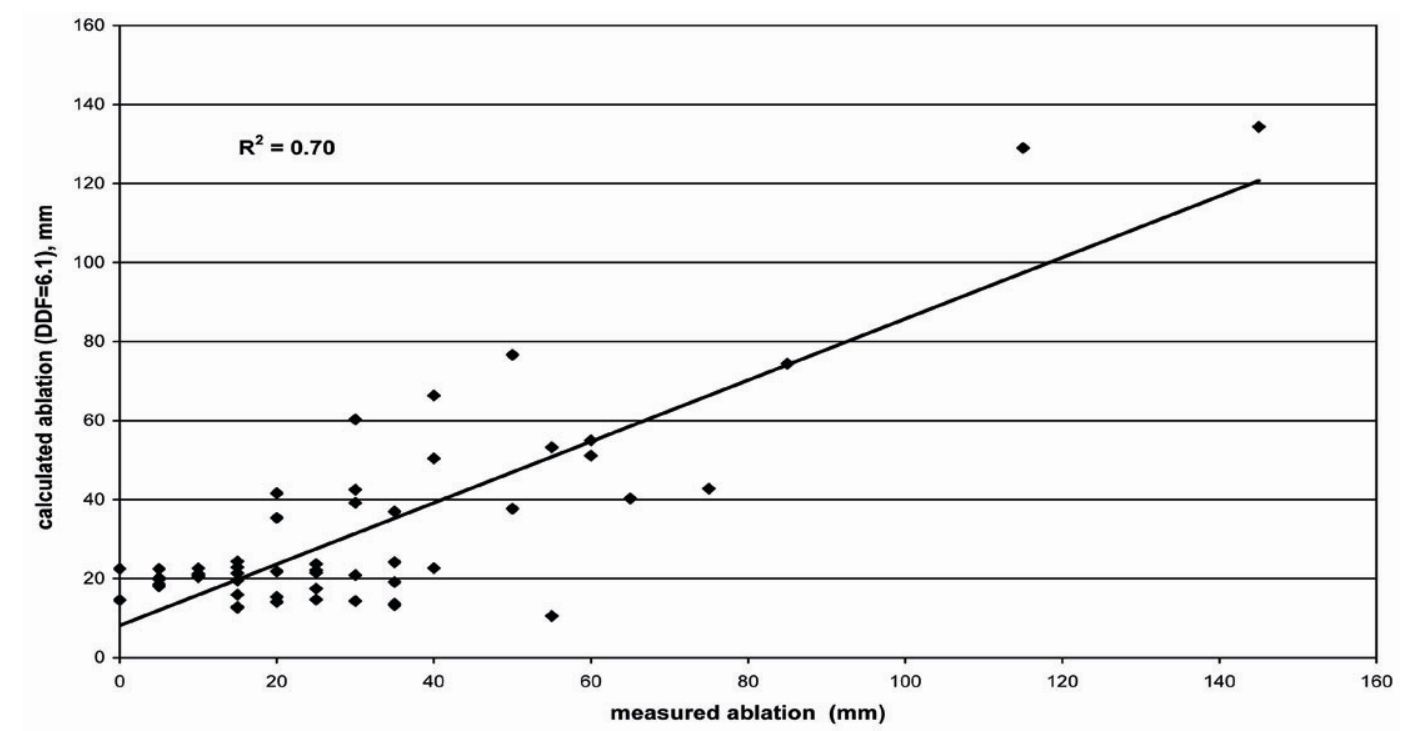

Fig. 5. Correlation between measured and calculated (using the mean degree-day factor of $6.1 \mathrm{~mm}^{\circ} \mathrm{C}-1 \mathrm{~d}-1$ ) ablation.

Some efforts have been made to improve the results of the degree-day approach by considering latent heat fluxes. Below the water vapour pressure (e) of $6.11 \mathrm{hPa}$, evaporation lowers the amount of melt energy and above this threshold, condensation delivers additional heat for melt. To account for these processes, index temperature was changed according to the water vapour pressure which can be calculated from relative humidity using the equation for relative humidity $(r H)$ :

$\mathrm{rH}(\%)=\frac{\mathrm{e}}{\mathrm{E}} * 100$

where $E$ is water vapour pressure for saturation conditions that was derived by the Magnus equation

$\mathrm{E}=6.1078 * \exp ^{\frac{17.0809 * \mathrm{~T}}{234.175+\mathrm{T}}}$

where $\mathrm{E}$ results in $\mathrm{hPa}$ and $\mathrm{T}$ is air temperature $\left({ }^{\circ} \mathrm{C}\right)$.

To account for latent energy fluxes, air temperatures have been modified linearly by adding the term

$\mathrm{a} *(\mathrm{e}-6.11)$

where $a$ is a tuning parameter.

All results using a positive, nonzero value for $a$ showed lower correlations with measured melt rates $\left(\mathrm{R}^{2}=0.61-0.66\right)$ than the original method using raw air temperatures. This shows 
that mean air temperature as an integral value for all thermodynamic processes is already a very good indicator for melt.

The thickness of debris cover has a strong effect on degree-day factors. To estimate ablation at a specific location, it is necessary to investigate the relation between DDF and debris cover (Fig. 6).

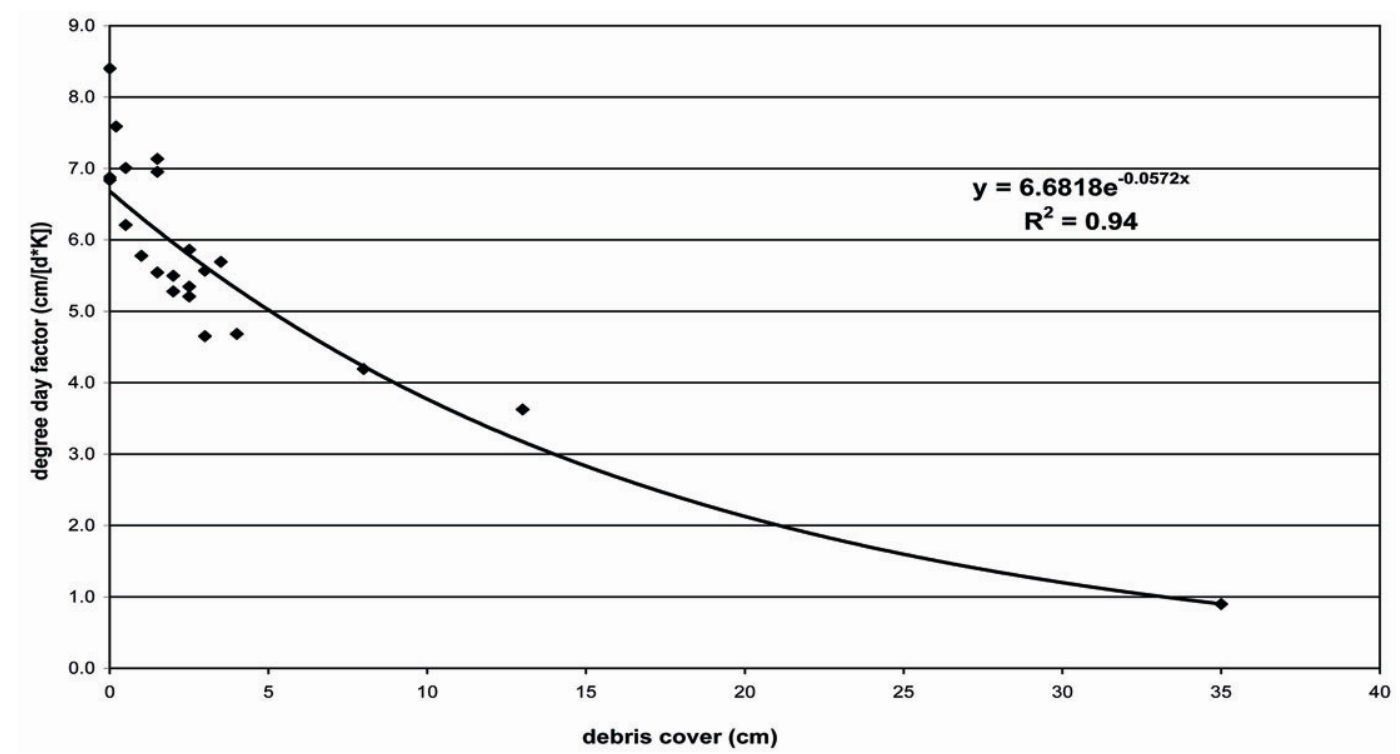

Fig. 6. Correlation between debris cover and degree-day factor.

The relative strong correlation of $\mathrm{R}^{2}=0.85$ allows an estimation of DDF from debris cover with the formula presented in Fig. 6. The so calculated ablation values are again compared to meaured ablation in Fig. 7.

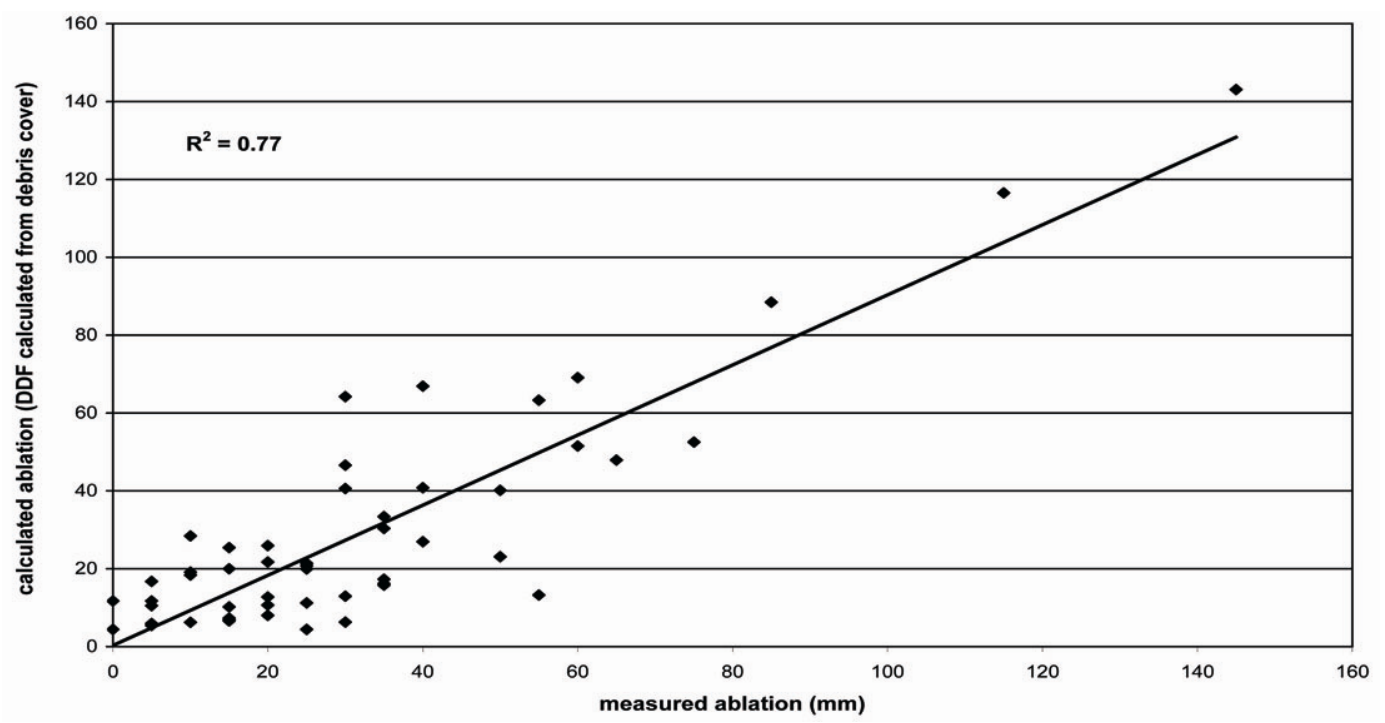

Fig. 7. Correlation between measured and calculated (using the degree-day factor calculated from the exponential correlation between DDF and debris cover) ablation. 
Using calculated DDFs (4.1-8.7, mean: 7.3) instead of the measured mean of 6.1 increases correlation with measured ablation from $\mathrm{R}^{2}=0.70$ to $\mathrm{R}^{2}=0.77$ and therefore delivers significantly better results.

\section{Ice albedo}

Ice albedo controls absorbance of shortwave radiation which is by far the major energy source and therefore a key factor for melt rates on glaciers. Especially on cloudless days, albedo measurements often show daily variations with maxima at sunrise and sunset and a minimun around solar noon. Some authors explain this by an artefact due to horizontal measurements over inclined surfaces (Müller 1985, Jonsell et al. 2003), others refer to angular dependences of pyranometers that result in growing uncertainties with increasing sun elevation (Kuhn, 1973). There are also hints that daily variation is controlled by the reflective characteristics of ice surfaces. Radiation partly penetrates the ice a few centimeters where it is scattered, filtered and partly reflected. Direct insolation is reflected mirror-like, without penetrating the ice. The growing portion of direct radiation with decreasing wave angle could cause the daily variation of ice albedo (Weber 2005).

Measurements of energy fluxes in the Alps (Weber 2005) have shown that evaporation favours the formation of small ice needles which have a higher albedo than smooth ice surfaces under condensation conditions. This effect was shown earlier for sublimation conditions on tropical glaciers (Kaser 1999, 2001), but seems to be true for evaporation as well. Under these circumstances, evaporation appears as energy sink in two aspects. First, it reduces the amount of available energy by forming ice surfaces that are more reflective and secondly it uses part of the absorbed energy which is not available for melting processes any more. Evaporation is much more ineffective for ablation than melt because it consumes seven times more energy. Water vapour pressure of the atmosphere is highly relevant for glacier melt, since it determines the occurrence of evaporation (below $6.11 \mathrm{hPa}$ ) or condensation. The preponderance of relatively dry air masses in the extremely continental climate of Central Asia may serve as a melt protection and favour the presence of glaciers.

In order to verify this hypothesis, ice albedo was measured on two days with differing meteorological conditions, using a horizontally mounted Pyranometer (Kipp and Zonen CM7B). 06.08. was overcast and wet with mean air temperature and humidity during observation of $7.9^{\circ} \mathrm{C}$ and $56 \%$, respectively. Conversely, 07.08. was cloudless and dry, yielding mean values of $12.1^{\circ} \mathrm{C}$ and $26 \%$ relative humidity. Ablation rates were $1 \mathrm{~cm} / \mathrm{h}$ on the cooler and $0.6 \mathrm{~cm} / \mathrm{h}$ on the warmer day, which illustrates the dominance of solar radiation as main energy source. Albedo was measured on a 10 minutes time step, results are shown in Fig. 8. 


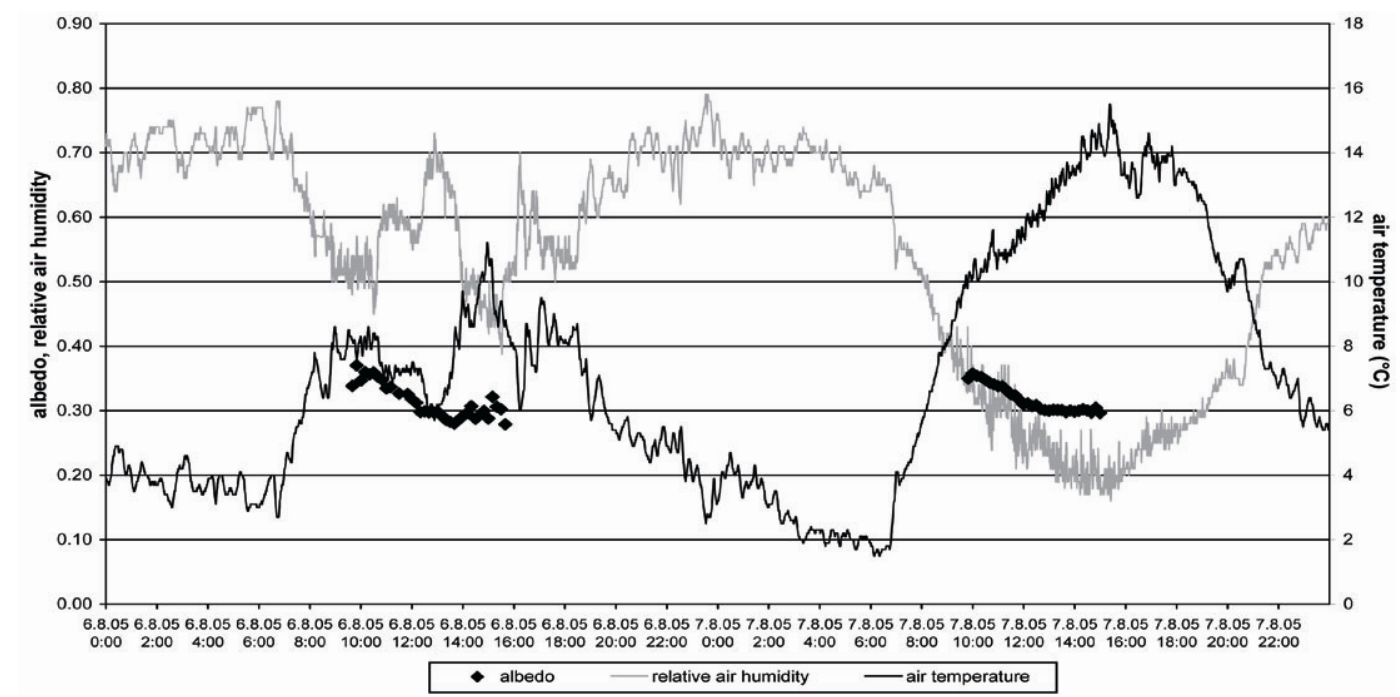

Fig. 8. Air temperature, relative aur humidity and albedo of bare ice on 06.08. and 07.08.

On both days, albedo showed a minimum from noon to early afternoon. On the first and second day, minimum albedo was 0.28 and 0.30 , respectively. These results point in the expected direction, but differences are quite small. This may be due to the fact that 06.08. was the last day of a relative moist weather period (mean rel. humid. 65\%) and there was not much time for the ice surface to change albedo on 07.08. according to the modified humidity. Assuming that the buildup of a typical "wet" or "dry" surface requires the endurance of one weather type over several days means that albedo would be higher in such a dry period and that differences between the periods would be more significant than observed. Unfortunately, weather and logistic circumstances did not allow albedo measurents on such a dry phase. Measured albedo values are in good agreement with typical values from the Alps, which range from 0.21 to 0.4 (Geiger 1961). This relatively broad range is due to the varying degrees of dust pollution, from clean to heavily dirty ice. Ice albedos from Central Asia are quite rare to find in literature, those from Djankuat glacier, Caucasus (0.34-0.42, Bozhinskiy et al. 1986) and Khumbu glacier, Himalaya (0.21 to 0.44, Takeuchi et al. 2000) show no significant differences to those observed in the Alps and. In this context it is necessary to point out that the comparability of albedo values depends on the time intervals of observation, which are not presented in most cases. Since albedo varies with the angle of the sun it makes a great difference if measurements were taken just around noon or from sunrise to sunset. To avoid such uncertainties, only daily minima should be contrasted. For further research on this topic, a comparable dataset of ice albedos from different glacier types and climatic settings has to be collected.

\section{Conclusion}

A dataset of ablation measurements on a moraine covered glacier in the Central Tian Shan is presented. At 22 ablation stakes with varying debris conditions, mean melt rates from 2.8 to $6.7 \mathrm{~cm} / \mathrm{d}$ have been observed. The decrease of melt with growing debris thickness is hyperbolic and agrees well with findings from other investigations. Meteorological measurements next to the glacier allowed the application of a degree-day approach to calculate ablation. Air temperature proved to be a very good index for melt and yielded better 
results than experiments to include latent fluxes in ablation calculations. Degree day factors at the stakes range from 4.1 to $9.3 \mathrm{~mm} /\left(\mathrm{K}^{*} \mathrm{~d}\right)$, with a mean value of $6.1 \mathrm{~mm} /\left(\mathrm{K}^{*} \mathrm{~d}\right)$. Calculation of ablation could be improved by using an empirically derived formula to calculate degree day factors from debris thickness. This kind of procedure enables fairly well the determination of sub-debris melt, without knowing thermal properties of the moraine layer. Once the relation between debris thickness and degree day factor is determined, melt can be calculated at all locations with known debris thickness. Such a conceptual approach should be further developed since it seems the only possibility to quantify melt over larger areas, whole glaciers or glacier systems. Physically based models require a large set of meteorological data and physical debris properties with great spatial and temporal variability, but this kind of data can be derived for point locations and for relatively short periods only.

A hypothesis concerning a predominating enhancing effect of evaporation on ice albedo in the continental climate was tried to be verified. Results are too few to be considered significant, but they point in the right direction and advert the necessity of future studies in this field.

Further research is also necessary concerning the detection of albedo from satelliet images. Due to the relation of debris surface temperature and debris thickness (Nakawo and Young 1981, 1982), remote sensing data should be used in further studies to detect the spatial distribution of debris thicknesses.

\section{Acknowledgements}

The expedition was organised and funded by the GeoForschungsZentrum Potsdam (GFZ) and supported by the Central Asian Institute for Applied Geosciences (CAIAG) in Bishkek. The authors thank those who made this collaboration possible, especially Wasili Michaijlow, Uli Wetzel and Christoph Reigber.

\section{Authors}

Dr. Wilfried Hagg, Department of Geography, Luisenstr. 37, 80333 Munich, Germany. Dr. Christoph Mayer, Commission for Glaciology, Bavarian Academy of Sciences and Humanities, Alfons-Goppel-Str. 11, 80539 Munich, Germany.

Dr. Astrid Lambrecht, Institute for Meteorology and Geophysics, University of Innsbruck, Innrain 52, 6020 Innsbruck, Austria.

Achim Helm, GeoForschungsZentrum Potsdam, Telegrafenberg, 14473 Potsdam, Germany. 


\section{References}

Bozhinskiy, A. N., Krass, M. S. and Popovnin, V. V. , 1986: Role of debris cover in the thermal physics of glaciers. Journal of Glaciology , 32: 255-266.

Braithwaite, R. J. , 1995: Positive degree-day factors for ablation on the Greenland ice sheet studied by energy-balance modelling. Journal of Glaciology , 41: 153-160.

Geiger, R. , 1961: Das Klima der bodennahen Luftschicht. Vieweg. Braunschweig. 646 p.

Jonsell, U., Hock, R. and Holmgren, B. , 2003: Spatial and temporal variations in albedo on Storglaciären, Sweden, Journal of Glaciology , 49:, 59-68.

Kaser, G. , 1999: A review of the modern fluctuations of tropical glaciers. Global and Planetary Change, 22: 93-103.

Kaser, G. , 2001: Glacier-climate interaction at low latitudes. Journal of Glaciology , 47: 195204.

Kayastha, R. B., Takeuchi, Y., Nakawo, M. and Ageta, Y. , 2000: Practical prediction of ice melting beneath various thickness of debris cover on Khumbu glacier, Nepal, using a positive degree-day factor. IAHS Publication No. 264: 71-82.

Khodakov, V. G. , 1972: A calculation of ice ablation under the moraine layer. Data of glaciological studies 20 , 105-108.

Konovalov, V. , 2000: Computations of melting under moraine as a part of regional modelling of glacier runoff. IAHS Publication No. 264: 109-118.

Kraus, H. , 1966: Freie und bedeckte Ablation. Ergebnisse des Forschungsunternehmens Nepal Himalaya, Lieferung 3, 203-236.

Kraus, H. , 1975: An energy balance model for ablation in mountainous areas. IAHS Publication No. 104: 74-82.

Kuhn, M. , 1973: Principles of the calibration of thermal radiometers, illustrated by the performance of 12 instruments in antarctic field work, Proceedigs of Symposium on Solar Radiation - Measurements and Instrumentation, Nov 13-15, 1973, Smithsonian Institution Radiation Biology Laboratory, 217-268.

Liu, S., Ding, Y., Shangguan, D., Zhang, Y., Li, J., Han, H., Wang, J. and Xie, C. , 2006:

Glacier retreat as a result of climate warming and increased precipitation in the Tarim river basin, northwest China. Annals of Glaciology , 43: 91-96.

Mattson, L. E. , 2000: The influence of a debris cover on the mid-summer discharge of Dome Glacier, Canadian Rocky Mountains. IAHS Publication No. 264: 25-33.

Mayer, C., Hagg, W., Lambrecht, A., Helm, A. and Scharrer, K. , submitted: Post-drainage ice dam response at Merzbacher Lake, Inylchek glacier, Kyrgyzstan. Geografiska Annaler , this volume.

Mihalcea, C., Mayer, C., Diolaiuti, G., Smiraglia, C. and Tartari, G. , 2006: Ablation conditions on the debris covered part of Baltoro Glacier, Karakoram, Annals of Glaciology, 43: 292-300.

Müller, H. , 1985: On the Radiation Budget in the Alps, Journal of Climatology , 5: 445-462.

Nakawo, M. and Young, G. J. , 1981: Field experiments to determine the effect of a debris layer on ablation of glacier ice. Annals of Glaciology , 2: 85-91.

Nakawo, M. and Young, G. J. , 1982: Estimate of glacier ablation under a debris layer from surface temperature and meteorological variables. Journal of Glaciology , 28: 29-34. 
Nicholson, L. and Benn, D. I. , 2006: Calculating ice melt beneath a debris layer using meteorological data. Journal of Glaciology , 52: 463-470.

Ohmura, A. , 2001: Physical Basis for the temperature-based melt index method. Journal of Applied Meteorology , 40: 753-761.

Østrem, G. , 1959: Ice melting under a thin layer of moraine, and the existence of ice cores in moraine ridges. Geografiska Annaler , 41: 228-230.

Popovnin, V. V. and Rozova, A. V. , 2002: Influence of Sub-Debris Thawing on Ablation and Runoff of the Djankuat Glacier in the Caucasus. Nordic Hydrology , 33: 79-94.

Singh, P., Kumar, N., Ramasastri, K. S. and Singh, Y. , 2000: Influence of a fine debris layer on the melting of snow and ice on a Himalayan glacier. IAHS Publication No. 264: 6370.

Takeuchi, Y., Kayastha, R. B. and Nakawo, M. , 2000: Characteristics of ablation and heat balance in debris-free and debris-covered areas on Khumbu Glacier, Nepal Himalayas, in the pre-monsoon season. IAHS Publication No. 264: 53-62.

Weber, M. , 2005: Mikrometeorologische Prozesse bei der Ablation eines Alpengletschers. $\mathrm{PhD}$ thesis, Institute for Meteorology and Geophysics, University of Innsbruck, $340 \mathrm{pp}$.

Yang, Z. , 1991: Glacier water resources in China. Lanzhou, Gansu Science and Technology Press. [in Chinese]. 